doi:10.5937/jaes9-1267

Paper number: 9(2011)4, 211, $465-472$

\title{
PROACTIVE TIRE MAINTENANCE
}

\author{
Dr Gradimir Danon * \\ University of Belgrade, Faculty of Forestry, Belgrade, Serbia \\ Miloš Petrović \\ Institute for research and design in commerce and industry, Belgrade, Serbia
}

Objective of the paper is to promote the proactive approach in tire maintenance for commercial vehicles and application of the Tire Pressure Monitoring System (TPMS). Researches have confirmed that the installation of TPMS on commercial vehicles is technically and economically justified, namely traffic safety and comfort of passengers would thus be significantly improved and operating costs would be decreased. Example of articulated city bus shows that the investment in the Tire Pressure Monitoring System would be recovered in the second year of operation.

Key words: tire, pressure control, traffic accident, costs

\section{INTRODUCTION}

From the end of the 1980's a lot of attention has been paid in professional and scientific journals to the problems connected with tire use and maintenance and potential dangers if the tires are not controlled and/or maintained regularly. It was determined that tires are very frequent cause of vehicle stopping. For example, in 2002 AAA (The American Automobile Association, Inc.) received 2.4 million calls from drivers who stayed on the roads because of deflated tires [15]. It was more than $50 \%$ of the total number of calls, namely almost 0.5 of tire failures per million vehicle/kilometres in the USA in the same year (2002). Number of failures is probably higher as it can be assumed that a significant number of drivers solved the "problem" and replaced the deflated tire with a spare one. The stated researches did not confirm usual statements that tire failures during driving were mostly the consequence of tire punctures. On the contrary, it was determined that more frequently these are failures as a consequence of thermal-mechanic loads of insufficiently inflated or overloaded tires, i.e. accelerated fatigue of material the tires were made of. Researches conducted in the USA showed that tires, beside the large number of failures, are not frequent cause of traffic accidents (only $0.5 \%$ of 6.3 million accidents that occurred in the USA in 2003) [01], however they have a high participation in "technical" accidents i.e. the accidents the cause of which was a vehicle system. For example, tire failures compose $21 \%$ of all technical accidents of trucks [15] or even $50 \%$ according to the data from Germany [07]. Figure 1 shows the structure of tire failures (causes of accidents with casualties or fatalities) in Germany.

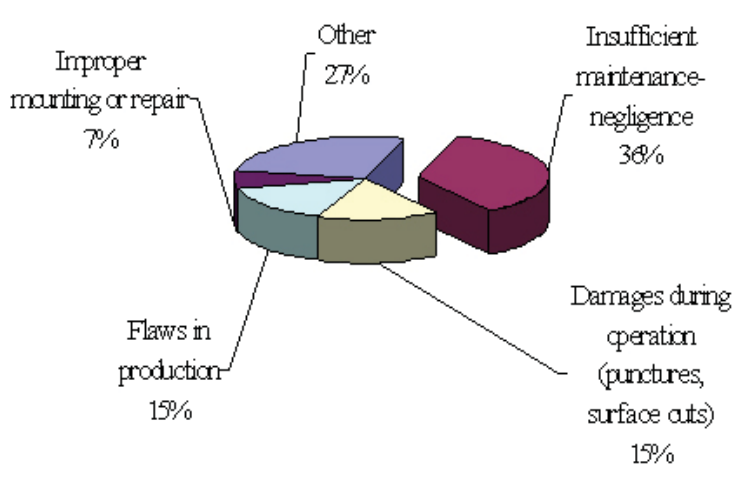

Figure 1: Causes of tire failures causing accidents with casualties or fatalities in Germany [11]

On the Figure it can be seen that negligence and poor maintenance of tires are the most frequent cause of accidents for which tires are marked as the main cause $(43 \%)$. Insufficient maintenance, or negligence, primarily implies insufficiently frequent control of tire pressure. According to the researches of the National Highway Traffic Safety Administration (NHTSA) on over 10,000 passenger and light trucks conducted in 2001 [15], $36 \%$ of the tested passenger vehicles and $40 \%$ of light trucks were found to have one or more tires under-inflated (by more than 20\%). The situation was not better among commer- 
cial vehicles. According to the study [02], almost $44 \%$ of tires on trucks and buses had the pressure ranging about 0.4 bar of the recommended pressure, and about $7 \%$ of tires had the pressure lower by more than 1.5 bar than the recommended pressure. Researchers in Serbia reached similar results as well [14, 05]. The situation is especially worrying regarding the pressure maintenance of dual tires for which (Figure 2) air pressure control could not be performed due to the lack of valve stem extender [05].

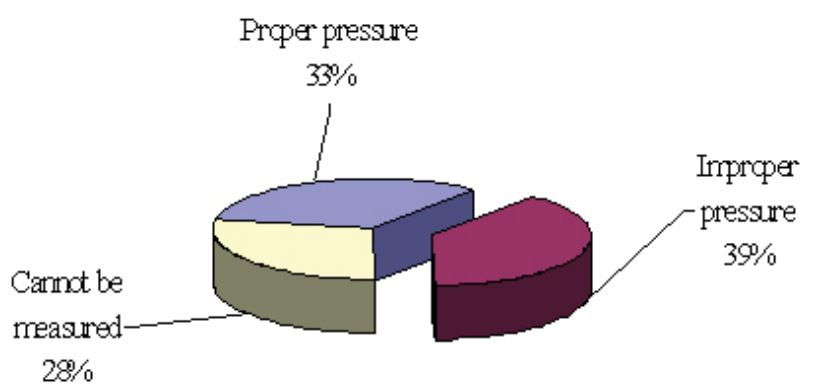

Figure 2: Results of air pressure control on city busses /16/

Common conclusion that can be made based on these researches is that the present maintenance of tires on passenger and commercial vehicles is not on adequate level, users do not pay sufficient attention to tires and they do not realize the importance of tires for safe driving. Also, it can be concluded that a large number of failures with happy ending was found which could act as a reminder that luck can be changeable and that lack of tire maintenance can significantly jeopardize traffic safety. One of the available opportunities for solving the problem of monitoring air pressure in tires is wider application of the Tire Pressure Monitoring System (TPMS) on cars and commercial vehicles. This idea is not new. More than fifteen years ago (in 1996) an article on TPMS for passenger and freight vehicles was published in "Commercial Carrier" journal [06]. The article analyzed devices used for monitoring air pressure in tires available at that time, as well as devices that enable pressure equalization in dual tires or pressure regulation, i.e. air inflation in tires. Based on this article and the information obtained from the companies that developed or sold these devices, an impression could be reached that these were already developed systems already commercially applied [09]. Unfortunately, the situation was not such. Lack of legislation (which appeared much later, first in the USA) and their price at that time limited the application of these devices to luxury passenger cars equipped with run-flat tires. Only after Ford - Firestone scandal [10] did the extensive researches start in the USA regarding the justification of using these devices [13]. These researches resulted with the TREAD regulation [11] that forbids the sale of new passenger cars without a TPMS device in the USA after 2006. The European Community adopted a similar regulation in 2009 with obligatory application for new vehicles from November 2014. Based on positive experience with passenger cars, the introduction of obligatory installation of TPMS also on trucks and busses is expected as the next step. To that effect, adequate researches have been conducted for several years already focused on the quantification of the impact of maintaining proper air pressure in tires of commercial vehicles in busses on safety and operating costs. Conclusion of these studies $[02,04]$ is that the realized savings in tire and fuel costs for commercial vehicles would pay off the investment in installing TPMS already in the second year of operation.

\section{TIRE PRESSURE MONITORING SYSTEM (TPMS) DEVICES}

Drivers traditionally avoid their obligations regarding tire maintenance. Despite various educational activities, no special advancement has been done and producers of tires and vehicles have searched for solutions which would "make the drivers' life easier" eliminating at the same time the main cause of tire failures, namely (instantaneous or gradual) loss of air pressure in tire. The simplest way is the sealants injected in the tire through the valve stem. The advancement in this area was made by Goodyear which offered tires with built-in sealants between two tire layers several years ago [12]. The best solution, however for passenger vehicles only, is the so called "run flat" tires. Run-flat tires are always accompanied with TPMS devices. These devices are, as previously mentioned, obligatory for all new vehicles sold in the USA from 2008 and from 2014 similar law will be in force in the European Community countries. Today, there are two types of these devices on the market, namely the ones that indirectly measure air pressure in tires by calculating the change of wheel radius from extensive tire speed and the others that directly measure the pressure (usually the temperature as well) and send the data to the driver's cab. 
Indirect systems - use the speed sensors of anti-lock braking systems. These sensors measure angular velocity of each wheel and based on this the computer calculates rolling radius which is in correlation with tire pressure among other things. Smaller rolling radius on a wheel means lower tire pressure. Too large differences in the calculated rolling radii activate alert signals in the driver's cab. Advantage of this system is that additional costs of installation are small if the vehicle is already equipped with ABS system.

Disadvantages of these devices are numerous:

- Proper functioning of the system requires reset after each inflation and set-up of the new condition. If the device is not set on the recommended pressure, calculation of rolling diameter will not be correct and the system will not react timely;

- Current indirect systems have different reactions for different speeds usually reacting only when the pressure drops to $30 \%$ lower value than the recommended pressure;

- Tires of different producers can have different elasticity characteristics and different rolling diameters (for the same load and air pressure), which can also impact the moment of system reaction;

- Insufficient pressure on all four wheels at the same time (which is a frequent case) is difficult to detect because of the manner of device operation.

- If the vehicle is not already equipped with ABS system, installation costs for indirect TPMS are significantly higher.

Direct systems - TPMS measures actual (over)inflation and temperature of air in tires. Sensors can be placed in the deepest groove on the wheel rim interior (in tubeless tires) or integrated with tire valve stem. Device in the cab receives signals from the transmitter and compares them with the previously given limit values for pressure and temperature. If the measured pressure or temperature exceeds the set limits, sound and/ or light alert is activated in the driver's cab.

Advantages of these systems are:

- Sensors are factory calibrated and do not have to be recalibrated;

- They operate with all usual tire types;

- They can also be used as measuring devices of air pressure in tires if the driver does not have it;
- It alerts the driver when the pressure drops below the set limit (which the driver can also change) and identifies the wheel where it occurred.

Disadvantage of direct TPMS systems is costs of procurement and installation in new and existing vehicles.

Regulations in the USA and Europe so far give preference to direct systems, therefore only these systems will be discussed hereafter. The set consists of a certain number of sensors (depending on the number of wheels on a vehicle) and receiver installed in the driver's cab. Example of the system for monitoring air pressure in truck tires is given on Figure 3 .

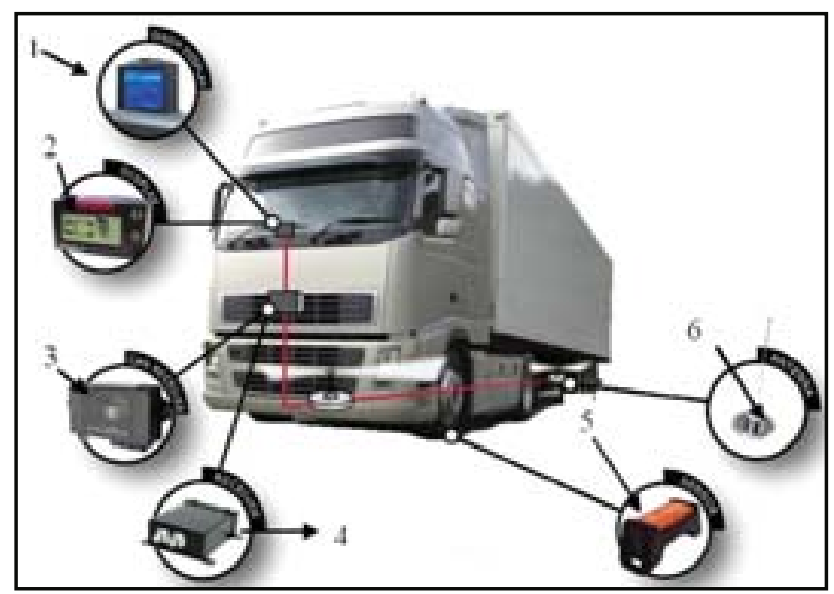

Figure 3: Example of tire pressure monitoring system for freight vehicles

Appropriate sensors (5) are installed on each wheel. Sensors measure air (over)inflation and temperature in tires. Signal from the sensors is transmitted via antennas (6) to the receiver (3 and 4) and finally to the display in the driver's cab (1). The measured (over)pressure is recalculated in the receiver for standard conditions $(20 \mathrm{oC})$ and compared with the set limit values. Many devices with sensors can be found on the market which are mounted on wheel rim by means of steel belt (see Figure 4).

Sensors for passenger cars, light trucks and heavy trucks are developed.

The second group consists of the sensors installed on the interior of the valve stem of tubeless tires (see Figure 5).

These sensors and valve stems are specially developed for the installation on the wheels of commercial vehicles. The sensor is installed on a standard valve stem and does not hinder 


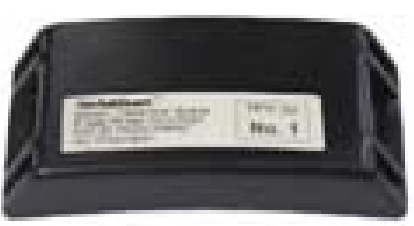

Sensor for passenger vehicles

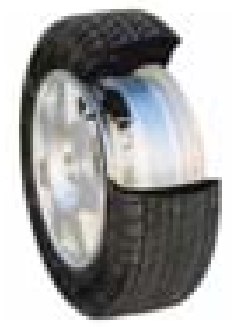

Transmitter installed on wheel rim

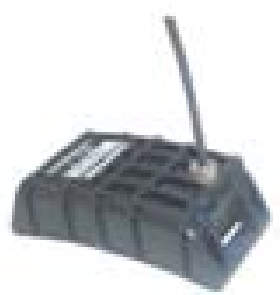

Sensor for passenger vehicles

Figure 4: Devices installed on wheel rim

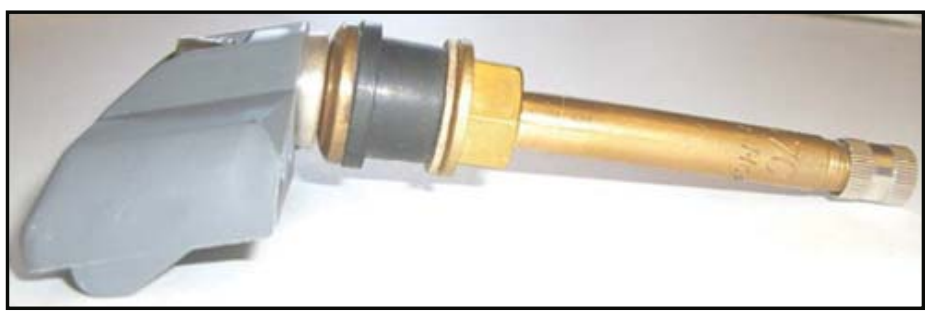

Figure 5: Sensor installed on valve stem

inflation and manual pressure control. There are two types of valve stems: the one made for steel and the other made for aluminium wheels. The advantage of these systems is that they are tougher, they have low profile, they are not easily damaged when mounting/dismounting tires and there is no need for a special antenna because the valve stem itself acts as one.

The third group consists of TPMS installed as valve caps. They are a simple and cheap do-ityourself solution, which can be used for passenger and freight vehicles (Figure 6).

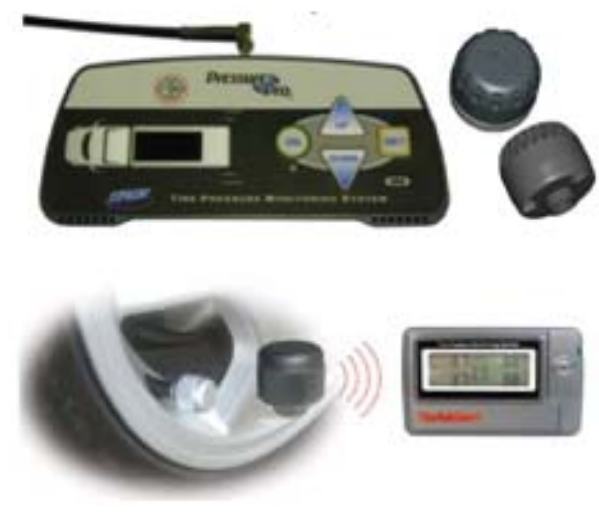

a) for passenger vehicles
Disadvantage of these sensors is that they have to be removed during inflation and they could become the target of inquisitive persons. Technical solutions allowing manual control or inflation of tires to their proper pressure without taking off the sensors can also be found on the market (Figure 7). These are the so called "Flow-Through" sensors which can be dismantled by means of special tools only.

The simplest solutions do not have this option. Sensors act as valve caps at the same time. Air pressure control in tires is done in various ways depending on the applied technical solution:

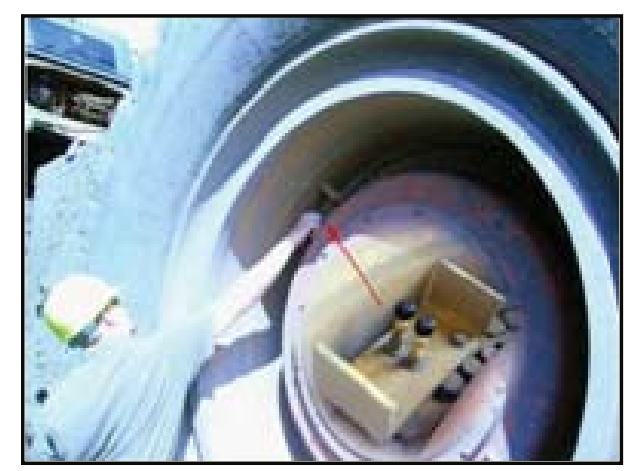

b) for freight vehicles

Figure 6: Valve caps - sensors for monitoring tire pressure

- In the driver's cab - most existing technical solutions also have adequate display in the driver's cab where it is possible to read temperatures and pressures in each tire separately. Driver can react on time and inflate the tire on the first petrol station or in the garage. Also, the system should react with sound or light signal if the pressure in one of the tires is lower than the set threshold (usually $80 \%$ of the recommended pressure); 

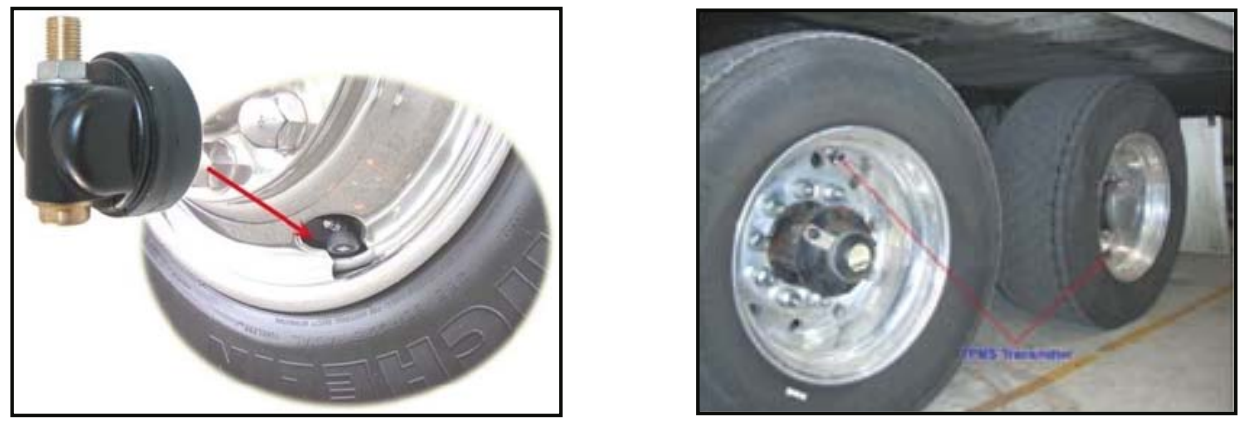

Figure 7: „Flow-Through" sensors for external installation

- In the garage - a stationary device is mounted which controls tire pressure on vehicles that enter or leaving the facility provided that they have adequate transmitters installed on wheels (see Figure 8). These way vehicles with deflated tires can be prevented from leaving.

The system is primarily intended for garages with a lot of vehicles whose daily movement radius and daily kilometres are relatively low.

- By means of a handheld device - maintenance worker has a personal digital assistant (PDA) and adequate software by means of which it can read air pressures in tires and record air pressure in tires in contact-less manner. If RFID (Radio frequency identification) is also installed in the tire, this device can also be used to read other data about tires.

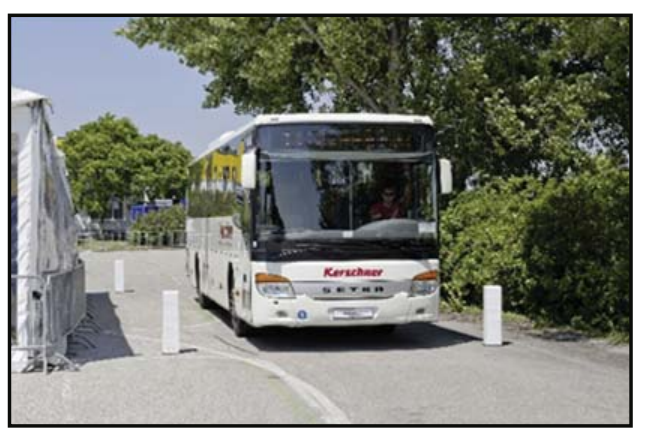

Figure 8: Control point for remote control of air pressure in tires

All text paragraphs should be single spaced, with first line intended by $10 \mathrm{~mm}$.

Double spacing should only be used before and after headings and subheadings as shown in this example. Position and style of headings and subheadings should follow this example. No spaces should be placed between paragraphs.

\section{JUSTIFICATION OF USING TPMS ON COMMERCIAL VEHICLES}

In the last several years, a lot of researches have been done with the objective to reject or confirm economic justification for applying TPMS devices [02, 08, 12].

Frequency of tire failures on passenger and freight vehicles, causes and consequences of these failures were researched. Objective of these researches was to determine if the realized savings would be higher than the costs of procurement, installation and maintenance of this equipment. Results of these and many other researches unambiguously indicate that improper air pressure in tires reduces the safety of passengers and vehicles and increases total operating costs. To quantify the effects of improper tire inflation, it was necessary to use "impact profile curves," which describe the correlation between the amounts a tire is under-inflated or over-inflated and the percentage impact on tire life, tread wear, and/or fuel economy [02].

Reduced tire life (total useable kilometres including all retreads - Inadequate tire inflation, specifically underinflation, causes a reduction in the useable life of a tire because the tire is running in an overloaded condition. Overloading causes the sidewall of the tire to extend and contract, causing heat generation inside the tire. Excessive heat leads to fatigue of the rubber and cords thus further exacerbating the sidewall flexing. The weakened structure increases the likelihood of punctures and cuts, and the increased temperature leads to premature separation between the tire cords and the rubber. In effect, the increased heat and motion reduces the number of times that a tire could be safely retreaded (see Figure 10). A common rule is that a constant $20 \%$ under-inflated condition will reduce the life of a tire by $30 \%$ and $40 \%$ under-inflation will reduce tire life by $50 \%$. 
- Increased tire wear (miles between retreading) - In addition to impacting the usable life of a tire, improper tire inflation also affects tread wear. Both over and under-inflation change a tire's footprint thus affecting tire traction and leading to irregular wear (see Figure 11). Under-inflation causes many types of irregular and accelerated wear patterns including shoulder wear, block-pumping wear, spot wear, diagonal wear, rib wear, and block-edge wear. Over-inflation also can cause shoulder and block-edge wear, and accelerates heel and toe wear.
A common principle is that a constant $20 \%$ underinflation will increase tread wear by $25 \%$.

- Reduced fuel economy - Fuel economy is also impacted by inadequate tire inflation. Increased flexing and the irregular footprint caused by underinflation, yields increased rolling resistance which leads to increased fuel consumption as more power is required to move the vehicle. In fact, for every 1 bar underinflation there is a $0.75 \%$ reduction in fuel economy. Figure 12 shows the impact profile of underinflation on fuel economy.

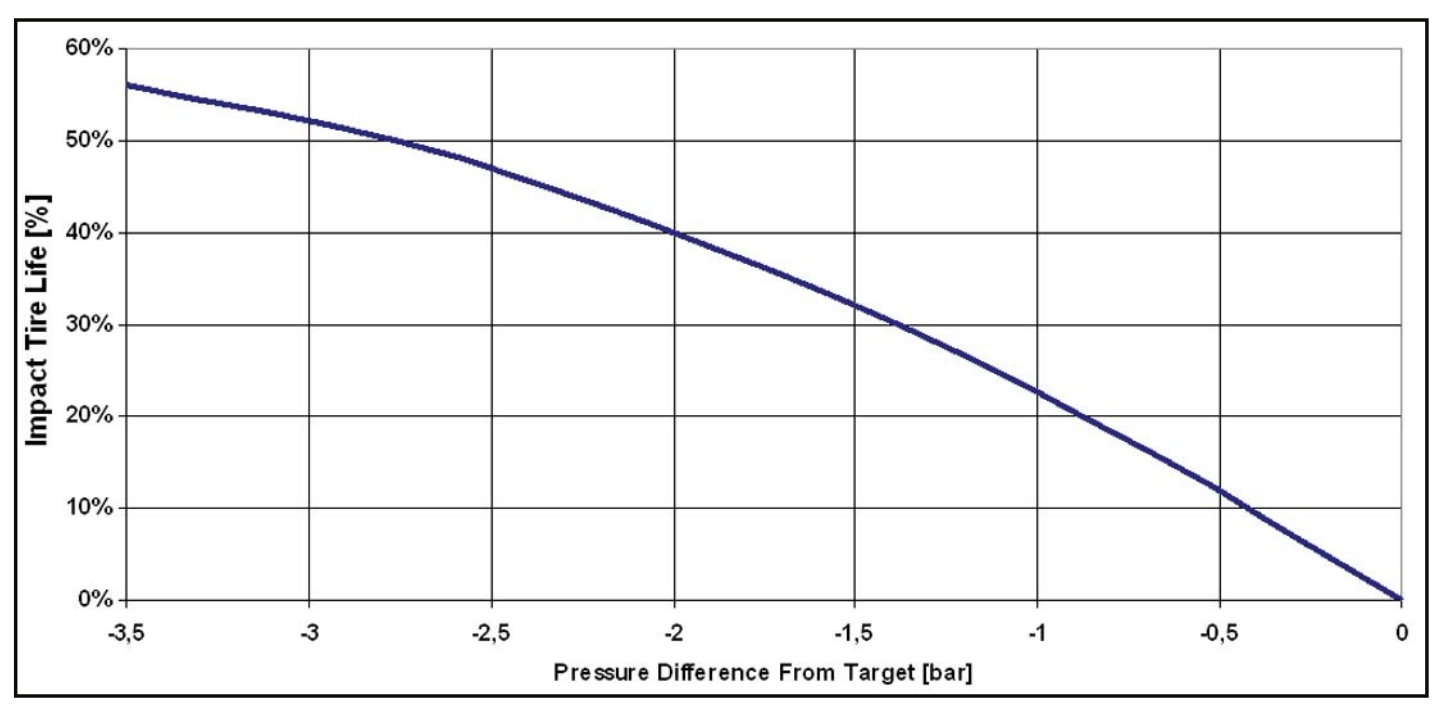

Figure 10: Underinflation impact of tire life [8]

- Tire failures from sudden loss of tire tread and blow-outs, leading to an out-of-service condition (road calls) - Under-inflation causes excessive deformation of the sidewalls and heat built up, which weakens adhesion between the rubber and steel cords. Improper tire inflation also increases the potential for tire failures from sudden loss of tire. Over-inflated tires also can lead to major tire failures since they are more vulnerable to tread surface cutting, impact breaks, punctures, and shock damage.

Based on the data from the same source [02], impact of under-inflated tires on operating costs

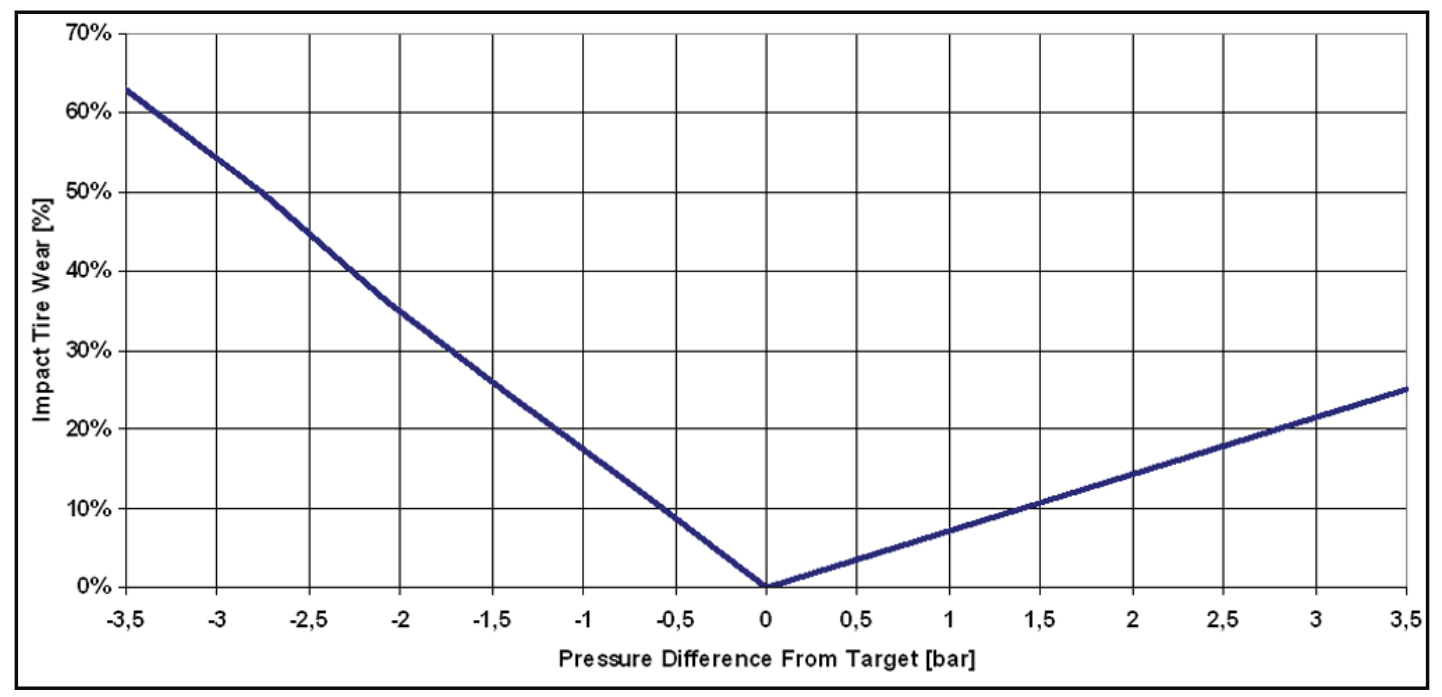

Figure 11: Inflation pressure versus tread wear [8] 
is calculated using a city bus in Belgrade as an example (see table 1).

Due to the reduction of tire life, the average of $7.67 \%$ of the price of a new tire is lost. Tire wear is $6.89 \%$ higher, which impacts the reduction of life of a new or renewed protector. Regarding fuel consumption, it is about $0.2 \%$ higher due to negligence in tire maintenance. Table 2 gives the required data for the calculation of possible savings. For this example, based on the assumed input data (given in table 3 ) and on the assumption that effects amounting to $80 \%$ of the expect-

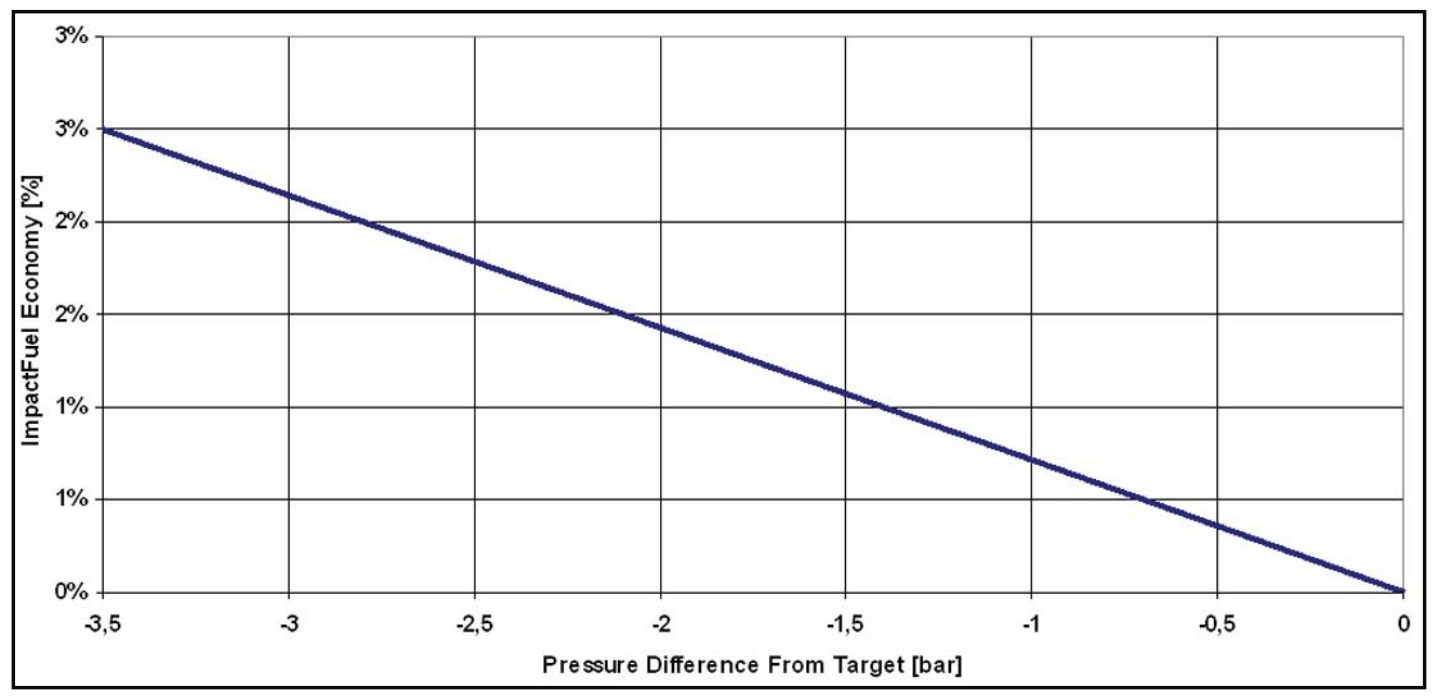

Figure 12: Underinflation impact on fuel economy

ed effects are realized with the introduction of TPMS, savings for one articulated bus in the amount of 471 EUR annually would be obtained. Vehicle with installed TPMS does not require frequent controls of air pressure in tires; how- ever, they are needed for occasional controls of proper functioning of the installed devices. Taking into consideration all these points and assuming that it will be possible to realize only $80 \%$ of the expected benefits, a bit reduced amount of savings is obtained (see table 4).

Table 1: Impact of improperly inflated tires of an articulated bus on operating costs [02]

\begin{tabular}{||c|c|c|}
\hline Reduction of tire life & Increase of protector wear & Increased fuel consumption \\
\hline$-7.67 \%$ & $+6.89 \%$ & $+0.19 \%$ \\
\hline
\end{tabular}

Table 2: Input data required for the calculation [03]

\begin{tabular}{|l|c|c||}
\hline Number of wheels on articulated bus & Number & 10 \\
\hline Average annual kilometres & $\mathrm{km}$ & 70,000 \\
\hline Average tire life & $\mathrm{km}$ & 54,000 \\
\hline Average consumption for articulated buses & $1 / 100 \mathrm{~km}$ & 70 \\
\hline Coefficient of tire retreading - average number of retreading in tire life & - & 0.11 \\
\hline Price of a new tire & EUR & 300 \\
\hline Price of diesel & EUR & 1 \\
\hline Average price of retreading & EUR & 150 \\
\hline Price of intervention in the field for 1 tire & EUR & 65 \\
\hline Number of interventions per vehicle annually & $\begin{array}{c}\text { Number of } \\
\text { interventions }\end{array}$ & 1 \\
\hline
\end{tabular}


Calculated savings should be compared with the costs of the user. These are the costs of procuring receivers and sensors (table 5).

Table 3: Possible savings that would be realized by installing TPMS on articulated bus [14]

\begin{tabular}{|l|c|}
\hline New tires EUR & 298 \\
\hline Retreaded tires EUR & 15 \\
\hline Fuel EUR & 93 \\
\hline Interventions on the road & 65 \\
\hline Total & 471 \\
\hline \hline
\end{tabular}

Table 4: Possible savings that can be achieved by installing TPMS on articulated bus [02, 08]

\begin{tabular}{|l|c||}
\hline $\begin{array}{l}\text { Reduced amount of savings for tires and } \\
\text { fuel ( } 80 \% \text { of } 471 \text { EUR) }\end{array}$ & 377 \\
\hline Retreaded tires EUR & 80 \\
\hline TPMS maintenance for one year EUR & -50 \\
\hline Possible savings EUR & 407 \\
\hline
\end{tabular}

Table 5: Costs of installing TPMS on articulated city bus

\begin{tabular}{||l|c|}
\hline Receiver EUR & 300 \\
\hline Sensors $\left(10^{*} 40\right)$ EUR & 400 \\
\hline Total $^{*}$ EUR & 700 \\
\hline \hline
\end{tabular}

Table 6: Comparison of costs and benefits

\begin{tabular}{||l|c||}
\hline \multicolumn{1}{|c|}{ Item } & Amount \\
\hline $\begin{array}{l}\text { Costs of installing TPMS on } \\
\text { articulated city bus EUR }\end{array}$ & 700 \\
\hline Possible annual savings EUR & 407 \\
\hline CBR (Cost-Benefit Ratio) & 1.72 \\
\hline
\end{tabular}

* Costs of installation are included in the price of a new bus. Now possible costs and possible benefits of installing TPMS on city buses can be determined (table 6).

It arises from the analysis that the funds invested in the installation of the system for controlling and monitoring air pressure and temperature in tires would be returned in less than two years or 21 month, i.e. by installing these systems the traffic would become safer, more comfortable and cost-effective.

\section{REFERENCES}

1) Anon. 2003. National Highway Traffic Safety Administration. Traffic Safety Facts 2003, DOT HS 809775.
2) Commercial Vehicle Tire Condition Sensors, Final Report, Booz Allen Hamilton Inc., Commercial Vehicle Safety Technology Diagnostics and Performance Enhancement Program Contract Number: DTFH61-99-C00025, 2003, p 97.

3) Cross R. Tire Pressure Monitors, Commercial Carrier Journal, No 64, 1996, pp 7 - 16.

4) Danon G, Mitrović Č. Opravdanost primene TMPS na gradskim autobusima GSP Beograd. Istraživanja i projektovanja za privredu, 6 (21), 2008, pp. 35-44.

5) Danon G, Petković M. Propisi i nove tendencije u proizvodnji i korišćenju pneumatika, u knjizi „Ka održivom razvoju“, Papić, V, Manojlović A, Univerzitet u Beogradu, Saobraćajni Fakultet 2011, pp 97-107.

6) Danon G. Važnost održavanja pritiska u pneumaticima komercijalnih vozila i mogućnosti njegove kontrole, XX Majski skup održavalaca, 1998. godina, pp 132 - 145.

7) Federal Statistical Office Germany, (Statistisches Bundesamt Deutschland), Accident reports by police at the accident location.

8) Gavrić P, Danon G, Momčilović V, Bunčić S. "Eksploatacija i održavanje pneumatika komercijalnih vozila", Istraživanja i projektovanja za privredu, 2009, vol. 7, no. 25, pp. 1-10.

9) Govindjee S. Firestone Tire Failure Analysis, Confidential Bridgestone/Firestone Document, 2001, p 73.

10) Grygier P, Garrott R, Mazzae E. An Evaluation of Existing Tire Pressure Monitoring Systems, DOT HS 809 297, National Highway Traffic Safety Administration, p 161.

11) http://www.bartecautoid.com/tyre_pressure_ monitoring_system.html

12) http://www.goodyear.com/cfmx/web/truck/ line.cfm?prodline $=160926$

13) http://www.tireindustry.org/pdf/TREAD_ ACT_Summary.pdf.

14) Lipovac K, Vukašinović M. Analiza stanja pneumatika na putničkim vozilima u Beogradu, Naučno- stručni skup "Pneumatici 2000", Vrnjačka Banja 1. - 3. juna 2000, Zbornik radova, OMO Beograd, pp 120 - 128.

15) Winsor J. 2003. Breakdown: 10 Top Reasons. Heavy Duty Trucking• January 2003, 38.

Paper sent to revision: 14.11.2011.

Paper ready for publication: 16.12.2011. 